\title{
Improved modeling of intelligent tutoring systems using ant colony optimization
}

\author{
Mahin Rastegarmoghadam ${ }^{1} \cdot{\text { Koorush } \text { Ziarati }^{1}}^{1}$
}

Published online: 4 March 2016

C The Author(s) 2016. This article is published with open access at Springerlink.com

\begin{abstract}
Swarm intelligence approaches, such as ant colony optimization (ACO), are used in adaptive e-learning systems and provide an effective method for finding optimal learning paths based on self-organization. The aim of this paper is to develop an improved modeling of adaptive tutoring systems using ACO. In this model, the learning object is personalized based on learning and solving problem styles. The purposed algorithm, based on ACO, generates the adaptive optimal learning path. The algorithm describes an architecture which supports the recording, processing and presentation of collective learner behavior designed to create a feedback loop informing learners of successful paths towards the attainment of learning goals. The algorithm parameters are tuned dynamically to conform to the actual pedagogical process. The article includes the results of implementation and experiment represent this algorithm is able to provide its main purpose which is finding optimal learning paths based on learning styles and improved performance of previous adaptive tutoring systems.
\end{abstract}

Keywords Adaptive learning $\cdot$ Swarm intelligence $\cdot$ Ant colony optimization $\cdot$ Learning style $\cdot$ Problem Solving style

\section{Introduction}

In recent years, we have seen exponential growth of Internet-based learning. The transition to online technologies in education provides opportunities to use new learning methodologies and more effective methods of teaching (Georgieva et al.

Mahin Rastegarmoghadam

rastegar.mahin@gmail.com

Koorush Ziarati

ziarati@shirazu.ac.ir

1 Department of Computer Science \& Engineering and Information Technology, Shiraz University, Molla Sadra Ave, NO. 2, Shiraz, Iran 
2003). But in web-based educational systems, the structure of the domain and content are usually presented in a static way, without taking into account the learners' goals, their experiences, their existing knowledge, and their abilities (Huang et al. 2007). This is also known as insufficient flexibility ( $\mathrm{Xu}$ and Wang 2006). This lack of interactivity means there is less opportunity for receiving instant responses and feedback from the instructor when online learners need support. Therefore, adding interactivity and intelligence to Web educational applications is considered an important direction of research (Hamdi 2007).

Personalization is an issue that needs further attention, especially when it comes to web-based instruction, where the learner population is usually characterized by considerable heterogeneity with respect to background knowledge, age, experiences, cultural backgrounds, professions, motivation, and goals, and where learners take the main responsibility for their own learning (Huang et al. 2007). Nowadays, slight modifications and supplements to e-learning systems are not enough to ensure successful e-learning outcomes, because other important elements for e-learning success are missing, such as system flexibility, adaptability in regards to student needs, and effective design of electronic content (e-content). This lack of an adaptive learning environment, or an environment with adaptive features, is partly due to the concept of "one-size-fits-all". Currently, emphasis is moving toward learner-oriented platforms, putting students' expectations, motivation, habits, learning styles, needs, etc. at the center of interest (Koper and Burgos 2005)

An e-learning system is considered to be adaptive if it is capable of monitoring the activities of its users, interpreting these on the basis of domain-specific models, inferring user requirements and preferences out of the interpreted activities, appropriately representing these in associated models, and, acting upon the available knowledge on its users and the subject matter at hand to dynamically facilitate the learning process. Since system behavior adapts to a person, this kind of adaptation is also called personalization. Thus, an adaptive e-learning system can be described as a personalized system, is able to provide adaptive course delivery, adaptive interaction, and adaptive collaboration support (Paramythis and Loidl-Reisinger 2004).

Personalized e-learning uses proactive learning strategies which enable learners to control learning content, pace, and scope. With these new technologies, learning content becomes rich and diverse owing to the use of hypermedia and multimedia presentations. Researchers have indicated that hypermedia systems are suitable for providing personalized learning support or guidance by identifying the personal characteristics of students and adapting the presentation styles or learning paths accordingly (Tseng et al. 2005).

Learning style is an important factor that has an influence on e-learning. An unacceptable learning style can lead to learner dissatisfaction (Harrington and Loffredo 2010). Researchers generally agree that learning styles play a vital and significant role in providing effective learning experience for learners. In adaptive style-based learning environments, the immense amount of available learning objects will increase cognitive overload for the learner (Jeroen and van Merriënboer 2005), and will lead to disorientation. These problems can be overcome using an adaptive learning path. Using an optimal learning path, learning objects can be provided in an effective way for the learner. That is, each learner can be provided with an individualized learning object depending upon their needs and contexts. 
Finding out an optimal learning path is an NP-hard problem. Ant colony optimization (ACO) plays a major role in providing adaptive learning paths (Kwasnicka et al. 2008). Besides ACO, many other approaches are extant for this curriculum sequencing problem. In e-Learning, ACO is the most used meta-heuristic for finding out an adaptive as well as optimal learning path. The natural behavior of ants is simulated with the help of a colony of artificial ant agents. An adaptive tutoring system looks for the particular group's learning patterns and prepares a suitable path for learners in accordance with these patterns. A group's learning patterns are a kind of swarm intelligence, which can provide an impressive level of adaptability for other homogeneous learners in this sort of dynamic learning environment (Pushpa 2012).

In this study, the proposed system builds on presented algorithms in the field and uses swarm intelligence in a graph-based path structure to provide an effective method for finding optimal learning paths based on ant colony optimization. In the algorithm's procedures, a new structure is created that increases performance efficiency and is more complete than previous models. We present ISACS as a method of finding optimal learning paths. ISACS is Improved the Style base Ant Colony System (SACS). Improvement is made by adding personalized parameters of system, changing the main factors in heuristic information values and pheromone updates, and optimizing the algorithm parameters to conform to the actual pedagogical process.

The article will proceed as follows. Section 2 will present a literature review of related studies for this research. Section 3 will offer the proposed algorithm, while Section 4 will discuss the implementation. Section 5 will describe the experimental evaluation. In Section 6, results will be discussed, and in the final section, conclusions and further work will be presented.

\section{Related work}

\subsection{Intelligent and adaptive tutoring systems}

"Intelligent tutoring system"(ITS) is a broad term, encompassing any computer program that contains some intelligence and can be used in learning (Mustafa and Mohamed 2011). Intelligent tutors offer relevant educational activities and provide feedback on those activities based on the learner's profile (Schiaffino et al. 2008). Identification of the learner's particular profile is the first phase of adaptation. The basis of didactical methods in intelligent tutoring systems is called the Learner Model. The Learner Model stores information concerning individual learners (especially the current knowledge state of learners). The Learner Model is a set of parameters containing the information about a learner's personality, experience, and education. It is important that each system is adaptive to a user.

Domain knowledge contains learning contents. The material presentation component enables presentation of learning content in different ways according to learner characteristics, on the basis of the regularly updated Learner Model. Data mining has a key role in adaptive models. By using intelligent analyses, it is feasible to connect particular concepts and content with student characteristics (i.e. learning styles). The user interface is responsible for creating the link between the learner and the system, without which no effective connection is established. The purpose of this module is to 
use peripheral devices to provide the student with necessary information and to receive his/her responses (Grasha 1984).

Adaptive educative systems try to offer an alternative to non-individualized approaches by providing several services adapted to the learner's profile. The goal of such adaptation is to maximize the subjective learner's satisfaction, the progress of learning, and evaluation results. For this strategy, there are three parts implemented in ITS:

- Defining a learner's learning style scheme.

- Providing learning objects dependent on learning style.

- Suggesting appropriate learning objects and learning paths using a swarm intelligence method (Ghusoon et al. 2013).

\subsection{Learning and problem solving style}

"Learning style" encompasses everything that is characteristic to an individual when she/he is learning: i.e. a specific manner of approaching a learning task, and/or the learning strategies activated in order to fulfill the task. According to a learning style represents, the composite of characteristic cognitive, affective, and psychological factors that serve as relatively stable indicators of how a learner perceives, interacts with, and responds to the learning environment (Keefe 1979). Landry claimed that "everyone has a unique learning style, and instruction should be designed to best accommodate different methods of learning." (Landry 2011). Each of the learning styles offers a set of principles and recommendations for the instructional strategies that should be used with the students pertaining to each category. Most psychologists recommend that the teaching style of the instructor should correspond to the learning style of the student (the "matching hypothesis"). Felder mentions that mismatching can have serious consequences: students may feel "as though they are being addressed in an unfamiliar foreign language. They tend to get lower grades than students whose learning styles are better matched to the instructor's teaching style and are less likely to develop an interest in the course material" (Felder 1993). Dunn and Griggs (2003) also suggest that teachers adapt the instruction and environmental conditions by allowing learners to work with their strong preferences and to avoid, as far as possible, activities for which learners report having very low preferences.

The broader concept of style has been linked with notions of learning style (Dunn and Dunn 1978), psychological type (Myers and McCaulley 1985), cognitive style (Kirton 1987; 1994), and, more recently, to problem-solving style (Selby et al. 2004a) is defined as consistent individual differences in the ways students prefer to plan and carry out generating and focusing activities in order to produce ideas and prepare for action.

There are many models for detecting learning styles. Some learning style models that we have gathered include those of Paramythis and Loidl-Reisinger (2004), Kolb, Felder and Silverman (1988), Dunn and Dunn (1978), MyersBriggs Type Indicator (MBTI). (VARK) styles the visual, aural, reading/writing and kinesthetic (Flemming 1995). Due to space limitation, we shall not 
elaborate on each of these learning style models, but only discuss those that are significant to our work.

\subsubsection{VARK model}

The VARK model is a style that is especially applicable in the presentation and organization of e-learning content in a self-paced e-learning course. This style is derived from the accelerated learning world, and seems to currently be the most popular model. (Schreurs and Moreau 2006). Its main strength is that it is quite simple, which appeals to many people (Maycock 2010). Learners use all four styles (visual, aural, $\mathrm{read} /$ write, kinesthetic) to receive information. However, one or more of these receiving styles is normally dominant. This dominant style defines the best way for a person to learn new information by filtering what is to be learned (Schreurs and Moreau 2006). In VARK, identifying a learner's style involves using an instrument to detect learning preference (Dunn and Griggs 2003). The instrument consists of 16 questions. There is only one answer for each question. Every answer corresponds to one of the four classes of learning styles. The responses are compiled by category and the maximum value is used to determine the respondent's learning style (Flemming 1995).

\subsubsection{MBTI model}

The Myers-Briggs Type Indicator (MBTI) can be easily connected to the learning styles of an individual learner in a more straightforward way than those outlined in other personality theories (Myers and McCaulley 1985; Myers 1993). MBTI has been widely used and validated in the educational domain (DiTiberio 1998), and has long been considered an important instrument by educational psychologists (Blaylock and Rees 1984; Stewart et al. 2005). The MBTI questionnaire divides personality traits into four distinct spectrums: Extroverted (E)/Introverted (I), Sensing (S)/Intuitive (N), Thinking $(\mathrm{T}) /$ Feeling $(\mathrm{F})$, and Judging $(\mathrm{J}) /$ Perceiving $(\mathrm{P})$. In addition to assessing personality, it can also be used to assess different problem-solving styles (Selby et al. 2004b). MBTI provides a basis for finding the relationship between personality traits and problemsolving styles. In this view, preferences in introversion/extroversion or thinking/feeling dimensions might prove useful in determining problem-solving style. It shows whether the individual, in dealing with the upcoming problem, prefers to act individually or in a group. For example, feeling-type learners tend to decide on subjective values, while thinking-type learners base their decisions on logic, facts, and objectivity (Felder and Brent 2005).

\subsection{Learner modeling methods}

In adaptive educational systems, the content of courses is tailored to the individual differences of learners by using a set questionnaire to determine the learner's learning style and then adapting their material presentation according to that style. As far as the creation of the learner model is concerned, Pham and Florea (2012) presented a concept that classifies modeling methods for learners as explicit and implicit modeling methods. Explicit modeling is a simple and straightforward method for inferring learners' learning styles. In this method, a dedicated measuring instrument (e.g. psychological 
questionnaire) is used in association with the learning style model. This method is labelled "explicit" as it requires direct input on the part of the student, who has to explicitly specify her/his learning style by filling in the questionnaire. In this way, a static learner model is created at the beginning of the course and stored permanently. Some disadvantages of this model are that:

- The measuring instruments used may not be reflective of the way a particular learner learns.

- The learners may not be aware of the importance of the questionnaires, and as such they may choose answers randomly.

- The learner model is too static, as once a learner model is created it is not subjected to change or update.

There is another method, which uses an implicit and/or dynamic modeling method. This method is based on already available feedback information, as well as the learners' interactions with the system. It determines a corresponding learning style without having to ask for additional effort from the part of the students. This may also have the advantage of being more accurate, overcoming the psychometric flaws of the traditional measuring instruments. Additionally, a dynamic modeling approach can be envisaged, with the learner model continuously updated during the learning process (Popescu 2008).

\subsection{Learning objects and learning paths}

A learning object (LO) is an independent content component that can function as the learning content of a course module. It can be defined as any digital content resource that supports learning that can be re-used and delivered on demand across the network. Examples of larger reusable digital resources include entire web pages that combine text, images, and other media to deliver course modules (Schreurs and Moreau 2006). The IMS Global Learning Consortium, the advanced distributed learning (ADL) co-laboratory, and others (MASIE Center 2002) have produced learning objects in their standardized works. Currently, the international Sharable Content Objects References Model (SCORM) (ADL 2004), based on the results of work done by the above-mentioned groups, is widely used in e-learning ecosystems. Many learning materials, such as multimedia, images, slides, or others components, may be packaged and placed in learning objects by SCORM. Thus, these related learning objects can be reorganized according to the sequence of a course (ADL 2004; IMS 2003), Furthermore, when learning content is to be created, organized, and placed in the sequence of a learning course, this sequence is similar to the path of that course. Accordingly, many web-based intelligence tutoring systems have developed sophisticated solutions for customizing learners' learning needs for meaningful learning relationships (Wang et al. 2008). An optimal adaptive learning path will help the learners reduce cognitive overload and disorientation, thereby improving the efficiency of the Learning Management System (LMS). Ant Colony Optimization (ACO) is a widely accepted technique as it provides an adaptive learning path to the learners. (Pushpa 2012) 


\subsection{Ant colony optimization in learning style-based adaptive educational systems (LSAES)}

An ant colony algorithm is a group of optimization algorithms inspired by ants exploring for food. Ants spread pheromones on the paths they navigate when finding food and returning to the nest. The first ant system (AS) was proposed by Dorigo (1992) and was successfully applied in tackling the wellknown traveling salesman problem (TSP) (Dorigo and Gambardella 1997). It is based on ant behavior when finding the shortest path between a food source and the nest. A single ant lays is equal pheromone and heuristic information to mark trails. When the paths are ranked by other ants, some of the trails may be reinforced and others paths may be allowed to evaporate. A trails' pheromone can be observed via the number of ants passing through the trail. An iterative local search algorithm tries to link the current paths to neighboring paths until a better solution is found. This meta-heuristic is inspired by the collective behavior of storing and path-tracking observed within ant colonies (Dorigo and Stützle 2004). Figure 1 shows the pseudo code of ACO.

Ant Colony Optimization (ACO) is a widely accepted technique since it provides an adaptive learning path to the learners. Meta-heuristic which is used in intelligent tutoring systems provides the learning path in an adaptive way. The most interesting feature of ACO is its adaptation and robustness in an environment where the learning materials and learners are changing frequently (Pushpa 2012). (Ghusoon et al. 2013) Propose a new dimension to detect learning styles, which involves the individuals of learners' social surrounding such as friends, parents, and teachers in developing a novel agent-based framework. The multi-agent system applies ant colony optimization and fuzzy logic search algorithms as tools to detecting learning styles. Pushpa (2012) presented the existing ACO approaches towards providing an adaptive learning path and an introduction towards an enhanced attribute ant for making the e-learning system more adaptive. Sharma et al. (2012) proposed an ant-based algorithm called Adaptive Content Sequencing in eLearning (ACSeL) for providing learning content to online learners. The algorithm evaluates the level of a learner and recommends appropriate concepts to him/her. It is sensitive to the changes in learning behaviours of each learner and fine-tunes its strategies to recommend the next concept accordingly. The behaviours of past learners are captured and utilized to recommend content to prospective learners. Wong and Looi (2009) propose the Dynamic Learning Path Advisor (DYLPA), a set of course sequencing algorithms that combine both prescriptive navigation rules and an inductive mechanism. Also utilizing the ACO technique, the Style-based Ant Colony System (SACS) (Wang et al. 2008) categorizes alumni into

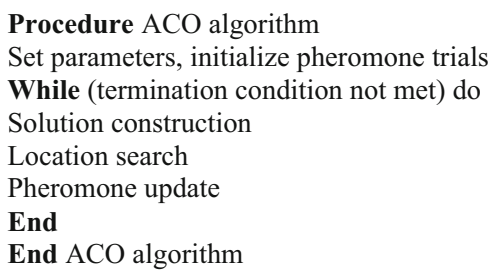

Fig. 1 pseudo code of Ant Colony Optimization algorithm 
four learning styles (visual, Aural/Auditory, Read/Write or kinesthetic). In recommending the next node, the pheromones deposited by the alumni who fall into the same category with the target learner are favored in the computations. The pheromone computation is not based on alumni performances, but merely the number of times the alumni have traveled. Gutiérrez et al. (2006) proposed a similar ACObased approach. In their approach, sequencing graphs record the frequencies and the performances ("successful" or "failed") of various paths that other learners have tried. The information is presented to the target learner every time he/she finishes a learning unit (a "node" in our context), so he/she can choose the next unit by referring to how all peers performed (i.e. the numbers of successful and failed peers) in the same situation. Van den Berg et al. (2005) developed a simplified ACO algorithm that only keeps the records of the paths selected by the learners who have successfully completed the course, as determined by a post course 5-question multiple choice quiz, by maintaining a transition matrix that records the number of learner transitions between individual pairs of nodes on such paths. The full path is then recommended to the next learner using the roulette wheel mechanism. Paraschool (Semet et al. 2003) applied the ACO heuristics to a pedagogic material navigation problem on e-learning, and experimented with an "ant-hill" method which laid the pheromone depending on how students validated an item (success or failure), so as to optimize learning paths with different students that have different views. Therefore, the ACO method seems well suited for tackling adaptive learning in a dynamic learning environment.

\section{The proposed algorithm (ISACS) ${ }^{1}$}

The algorithm presented in this section has been provided after conducting research into each of the previous methods. Building on previously presented algorithms in this field, we present ISACS as a new method for finding optimal learning paths. In the algorithm's procedures, a new structure is created that increases performance efficiency and complete the previous models. ISACS is Improved the Style base Ant Colony System (SACS) algorithm. To achieve this, we have:

1) Added personalized parameters to the system.

2) Change in the main factors for heuristic information value and pheromone update.

3) Optimized algorithm parameters to conform to the actual pedagogical process.

In this system, we assumed that each concept was taught by several teachers with different teaching styles, thus adapting the VARK model. For example, a teaching style could be called visual when it includes the depiction of information in maps, spider diagrams, charts, graphs, flow charts, labeled diagrams, symbolic arrows, circles, hierarchies, and other devices, as opposed to presenting this information in words. It does not include only pictures, photographs, movies, videos or PowerPoint, but also designs, whitespace, patterns, shapes, and other different formats that are used to highlight and convey information and educational elements. This emphasis on graphics sets it apart from other methods of learning, such as aural, text or kinesthetic. When the

$\overline{1}$ - Improved Style base Ant colony System 
teacher uses a whiteboard to draw a diagram featuring meaningful symbols for the relationship between different things, this will be helpful for those with a preference for the visual learning style. Each exercise is designed according to the MBTI preference of the learner in order to help the student solve the problem better (see Table 1).

The graph structure of a course sequence includes content-groups and exercisesgroup modules (Fig. 2). Each content represent the -group $C_{i}$ matches a different learning style, and each exercise-group $E_{i}$ matches a different problem solving style, including questions related to the concept. The questions posed in each exercise are designed according to the MBTI model. The goal is to further use these as prerequisites to match the relationships between learners and learning object in order to maximize the mean score and minimize the time taken to pass a course (obtained over the period).

The algorithm presented in this section as a solution to the above problem is based on ACO algorithm. Like the Ant-Cycle version, once all the ants have constructed their paths, the pheromone trails are updated in the each iteration due to increased efficiency. The amount of pheromone left by each ant will be a function of the response quality, as well as the obtained result. There are two main phases in this algorithm, as in algorithms derived from AS construction solutions: constructing optimal learning paths and updating the pheromone.

\subsection{Construction of learning paths}

At the beginning, a learning object is randomly assigned to each ant. At every stage of constructing the learning path, the $\mathrm{k}$-th ant uses a probable selection law system called

Table 1 Designing learning objects to adapt to learning \& problem-solving styles

\begin{tabular}{|c|c|c|c|c|}
\hline \multirow[t]{2}{*}{ SI NO } & \multicolumn{2}{|l|}{ Learner Attributes } & \multicolumn{2}{|c|}{ Learning Object(LO) Attributes } \\
\hline & $\begin{array}{l}\text { VARK's Learning } \\
\text { style }\end{array}$ & $\begin{array}{l}\text { MBTI' s Problem Solving } \\
\text { styles }\end{array}$ & Content Type & Exercise Type \\
\hline 1 & Visual & Introversion/ thinking & $\begin{array}{l}\text { Provide the content with } \\
\text { more visual materials such } \\
\text { as pictures, videos, } \\
\text { posters, flowcharts, } \\
\text { graphs, diagrams. }\end{array}$ & $\begin{array}{l}\text { Provide structural, } \\
\text { analytical and } \\
\text { logical exercises } \\
\text { on an individual } \\
\text { basis }\end{array}$ \\
\hline 2 & Aural/Auditory & Introversion/ feeling & $\begin{array}{l}\text { Provide the content with } \\
\text { more aural materials such } \\
\text { as PowerPoint slides or } \\
\text { animation with audio, } \\
\text { stories. }\end{array}$ & $\begin{array}{l}\text { Provide the open } \\
\text { and creative } \\
\text { exercises on an } \\
\text { individual basis }\end{array}$ \\
\hline 3 & Read/Write & Extroversion/ Thinking & $\begin{array}{l}\text { Provide the content with } \\
\text { more text materials such } \\
\text { as documents, lists, } \\
\text { headings, definitions, text } \\
\text { books, manuals. }\end{array}$ & $\begin{array}{l}\text { Provide structural, } \\
\text { analytical and } \\
\text { logical exercises } \\
\text { on a group basis }\end{array}$ \\
\hline 4 & Kinesthetic & Extroversion/ Feeling & $\begin{array}{l}\text { Provide the content with } \\
\text { more kinestheitic } \\
\text { materials such as hands- } \\
\text { on labs. }\end{array}$ & $\begin{array}{l}\text { Provide open and } \\
\text { creative } \\
\text { exercises on a } \\
\text { group basis }\end{array}$ \\
\hline
\end{tabular}




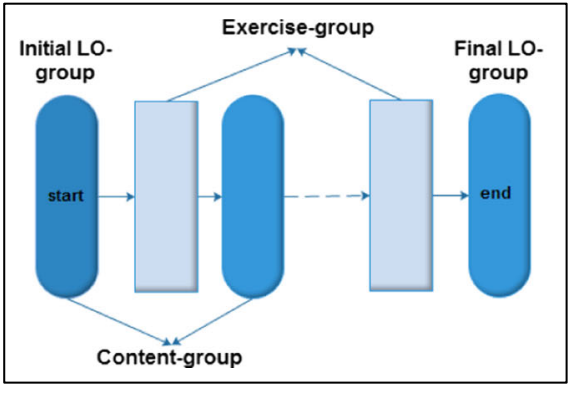

a

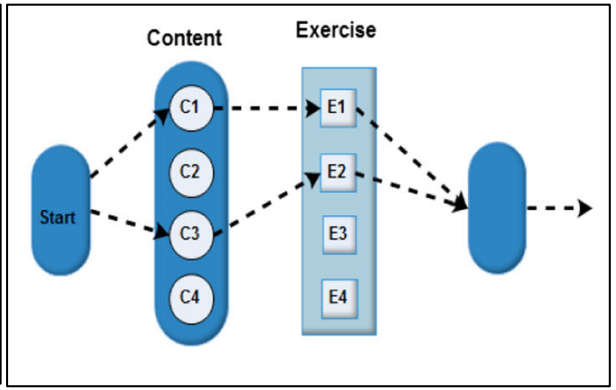

b

Fig. 2 a A Graph structure of a course sequence with content-group and their exercises-group in the proposed model. $\mathbf{b} \mathrm{C}_{\mathrm{i}}$ represents the content adaptation to VARK learning styles, and $\mathrm{E}_{\mathrm{i}}$ represents the exercises adapted to MBTI problem-solving styles

randomized comparative law in order to select the next learning object. The probability of the k-th ant being located on $\mathrm{LO}_{\mathrm{i}}$ and wanting to select $\mathrm{LO}_{\mathrm{j}}$ is calculated in Eq. 2 .

$$
P_{i j}^{k}(t)=\frac{\left|\tau_{i j}(t)\right|^{\alpha}\left|\eta_{i j}(t)\right|^{\beta}}{\sum_{\mu \in N_{i}^{k}}\left|\tau_{i \mu}(t)\right|^{\alpha}\left|\eta_{i \mu}(t)\right|^{\beta}} \quad \text {, if } j \in N_{i}^{k}
$$

In this equation, $N_{i}^{k}$ is the series of learning objects allowed to be selected at each stage, showing the sequence and priority of learning concepts. $\eta_{i j}$ is heuristics information, $\tau_{i j}$ is the pheromone trail, and $\alpha$ and $\beta$ are parameters that indicate the relative importance of the pheromone trail and heuristics information in selecting the next learning object.

\subsection{Heuristics information}

Heuristics information, as defined in this algorithm, is derived from the SACS algorithm. However, the formula defined in this study is fitted to be closer to the values of the forgetting curve. $\eta_{i j}=R_{i j}$ is a heuristics value which is inversely proportional to the time, and is derived from the unit-time learning forgetting curve (Ebbinghaus 1913) that continuously represents the decline in the learning data of the learner. The memory coefficient (R), which represents the learning loss over time, is shown below using a descending exponential function and two constants of $\mathrm{s}$ and to adjust to real learning situations:

$$
R_{i j}=\frac{1}{1+\frac{1}{\lambda s} \ln \left(1+\lambda t_{i j}\right)}
$$

this equation, $t_{i j}$ is the time duration between node $\mathrm{i}$ to node $\mathrm{j}, \lambda$ is the learning constant, and $\mathrm{s}$ is relative power of the memory which is proportional to the number of iterations of a subject. The greater value of $R_{i j}$ represents the greater ability of a learner to recall the information contained in the $\mathrm{i}$-th node when going to the $\mathrm{j}$-th node. 


\subsection{Local search}

When learning paths are constructed by learners, they are improved by a process of local search, Learners whose mean score along the path is in pass mode, and where the total time they have spent studying learning objects has not passed a certain limit, are considered to be the best ants, and are then selected so their experience can be used in the next iterations.

\subsection{Updating pheromone trails}

Selecting appropriate parameters to update the pheromone can play an important role in highlighting the paths in which learners are performing best. The performance indicators of learners in selecting a course concept include the completion of exercises in less time and achievement of higher scores. In the proposed algorithm, the amount of pheromone increase for each learner is dependent on three main parameters:

1) The time duration between the ith node to the jth node (the forgetting parameter).

2) The time an ant spends studying a course concept and doing exercises.

3) The score that an ant obtains from doing the exercises related to the course concept.

In this case, the $\mathrm{j}$-th node is a course concept, the score and time taken to do an exercise are equal to zero, and only the value of $\mathrm{R}$ is considered. In each iteration, only the ants with the best results in a specified time interval (Best Ants) are allowed to add pheromone. This value is defined as follows:

$$
\tau_{i j}(t)=\tau_{i j}(t-1)+\sum_{K=1}^{m} \Delta \tau_{i j}^{k}(t) \quad \forall(i, j) \in L, \quad k \in \text { BestAnt }
$$

In this equation, $\Delta \tau_{i j}^{k}$ is the amount of pheromone that the $\mathrm{k}$-th ant leaves on the edges it had crossed.

$$
\Delta \tau_{i j}^{k}=\left\{\begin{array}{c}
Q\left(R_{i j}+\left(\frac{S_{i j}^{k}}{S_{\max }} \times \frac{1}{T_{i j}^{k}}\right)\right) \\
0, \quad \text { otherwise }
\end{array} \text { if } \operatorname{arc}(i, j) \in L_{k}, k \in\right. \text { BestAnt }
$$

In this equation, $S_{i j}^{k}$ is a score that the $\mathrm{k}$-th learner has earned and $T_{i j}^{k}$ is a time that has been spent on studying $c_{i}$ and doing the exercise $e_{j}$. $S_{\max }$ is the highest score by all learners that have already passed the edge $(i, j) . L_{k}$ is the learning path traveled by the kth ant.

In this algorithm, the idea of similar ants expressed in the SACS algorithm (Wang et al. 2008) has been used to follow the paths that are most accommodating with learners' traits in terms of learning and problem-solving styles. Pheromone changes for using adaptive learning rules on the edges $(i, j)$ are as follows: 


$$
\Delta \tau_{i j}(t)=\sum_{n=0}^{\vartheta}(\vartheta-n) \Delta \tau_{i j}^{k, \text { style }}(t)+\sum_{n=1}^{\sigma} \Delta \tau_{i j}^{k, \text { rank }}(t)
$$

where $\Delta \tau_{i j}^{k, s t y l e}(t)$ and $\Delta \tau_{i j}^{k, \text { rank }}(t)$ are variable amounts of pheromone left on the edges $(i, j)$ from the time $t-1$ to the time $t$, the former indicating changes in pheromone by ants that have a similar learning style with the k-th ant. $\vartheta$ is the number of learners with the same style, representing changes in pheromone of all the ants regardless of their style. $\sigma$ is the number of learners that have crossed the edges $(\mathrm{i}, \mathrm{j})$.

To update the pheromone trails, some pheromone is subtracted from all edges by an initialized constant, then spread over the edges that the best learners have crossed in their learning paths. Pheromone evaporation in this algorithm is implemented by the following formula:

$$
\tau_{i j}(t)=(1-\rho) \tau_{i j}(t-1)
$$

In this equation, $\rho$ is the pheromone volatilization rate per unit of time $(0$ $<\rho<1)$. After performing volatilization, the best ants leave pheromone trail on the edges that they have crossed on their own learning path.

\section{Algorithm implementation}

1. Initialization of parameters: Initializing include: 1) Algorithm parameters. 2) Lists of the nearest neighbor to all learning objects. (In this issue, due to continuity and the order that should be observed in presenting concepts of a course content, a list of neighbors is considered for selecting the next learning object). 3) Pheromone matrix and matrix of heuristic values. 4) Ants must be initialized. For each ant, structural data must be defined for stored learning styles, attention skill, time duration between node $i$ to node $j(t)$, time spent for content study or problemsolving $(\mathrm{T})$, scores, learning paths, and heuristic information matrix.

2. Construction of Solution: an initial LO should be assigned to every ant. In this implementation, we have assigned the learning object which is assumed to have the greatest similarity to the learner's learning style as an initial LO to the k-th ant. Each ant travels a learning path within the interval $t, t-1$. At each step of selecting the path, ants apply the choice act (relation 5). Their learning path during this time interval and the selected LO is placed in the learner's learning path.

3. Computation of Heuristic Information: In this algorithm, the heuristic information value is dynamic. For each arc $(i, j)$, the time duration between node $i$ to node $j$, $\mathrm{t}$, is the input parameter for Eq. (3) to compute heuristic value.

4. Local Search: In this implementation, the score of each learner is a number within the range of 0 to 100 . To achieve success, the minimum score of 60 must be obtained, and the total time spent on studying or doing exercises and the total time spent on selecting between two learning objects must be less $\theta$. $(\theta$ assumes 4.5 
according results for this problem). A learner is considered as the best ant if this condition is met, and the pheromone is only updated for this group of learners.

5. Updating Pheromone: After the pheromone is updated, ants are classified according to their learning style. The pheromone related to each group is stored in a separate matrix. Each ant, according to its learning style, will use the pheromone matrix related to its own group in the next iteration. These procedures are shown in Fig. 3.

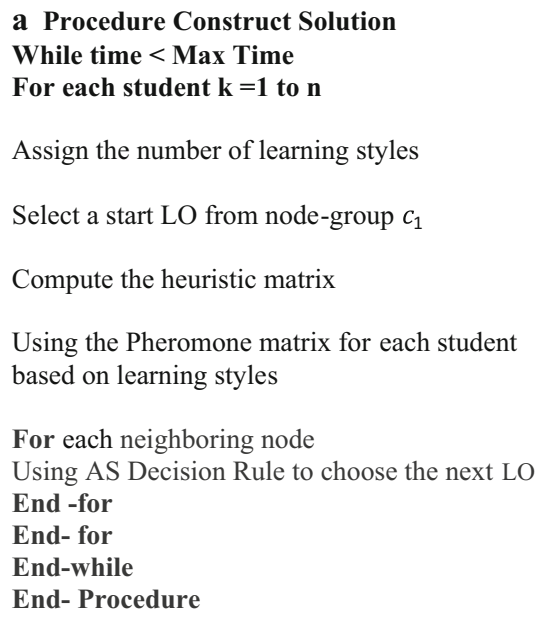

\section{b Procedure Heuristic Information \\ For each student $\mathrm{k}=1$ to $\mathrm{n}$ \\ Computing the time between two nodes $\left(t_{i j}\right)$. Computing respectively the learning rate $\mathrm{R}$ \\ Where $R_{i j}=\frac{1}{1+\frac{1}{\lambda s} \ln \left(1+\lambda t_{i j}\right)}$}

End for

End for

End Procedure

\section{c Procedure Local Search}

For each student $\mathrm{k}=1$ to $\mathrm{n}$

Computing the sum of time spent for each LO Computing the mean of score for each exercise If the sum (stu (k).time) $<\theta$ \& mean (stu (k).score) $>\delta$ Best student $=$ student $\mathrm{k}$ End if

End for

End Procedure

\section{d Procedure Pheromone Deposit}

For every best students $k=1: n$

For each $\operatorname{arc}(\mathrm{i}, \mathrm{j})$ in the best student's path

$$
\begin{aligned}
& \Delta \tau_{i j}^{k}(t)=Q\left(R_{i j}^{k}+\left(\frac{S_{i j}^{k}}{S_{\max }} \times \frac{1}{T_{i j}^{k}}\right)\right) \\
& \Delta \tau_{i j}^{\text {rank }}(t)=\sum_{n=0}^{\vartheta} \Delta \tau_{i j}^{k}(t)
\end{aligned}
$$

Where $\sigma$ is the rank of student on $\operatorname{arc}(\mathrm{i}, \mathrm{j})$

Categorize best students based on learning \& problem styles

$$
\Delta \tau_{i j}^{k, s t y l e}=\sum_{n=0}^{\vartheta}(\vartheta-n) \Delta \tau_{i j}^{k}
$$

Where $\vartheta$ is the total number of students with the same styles on arc $(i, j)$

$$
\tau_{i j}(t)=\tau_{i j}(t-1)+\Delta \tau_{i j}^{k, s t y l e}(t)+\Delta \tau_{i j}^{\text {rank }}(t)
$$

End for

Fig. 3 Proposed algorithm in pseudo code; a Pseudo code of construct solution, b Pseudo code of computing heuristic information, $\mathbf{c}$ Pseudo code of local search, $\mathbf{d}$ Pseudo code of updating pheromone trails 


\section{Experimental evaluations}

\subsection{Analyzing the heuristic information values}

The main role of heuristic information is to avoid constructing responses with poor quality. In the SACS algorithm, based on the ACO, the value of the heuristic function is obtained from the equation:

$$
R_{i j}=e^{-\left(c \cdot \frac{t_{i j}}{s}\right) 2}
$$

This is a relation to indicate the forgetting curve. The $R_{i j}$ curve behavior, which was improved in the previous research by the dynamic parameter $\mathrm{c}$, is still far from the actual values of the forgetting curve. However, it still does not coincide, completely forgetting curve values. In this paper, this function is fitted to Eq. (3), by reasons given in the section (6.1).

\subsection{Dynamic tuning of the algorithm parameters}

Despite the effectiveness of meta-heuristic algorithms such as ACO in solving decisionmaking and optimization issues, this algorithm requires high precision while carrying out the tests. Improper adjustment of algorithm parameters causes reduced efficiency and effectiveness. In the proposed algorithm, the most efficient method for adjusting the parameters is one which considers the entire space. for solutions at the beginning of the search. It identifies all possible learning paths and moves towards optimal trails. Two types of local or global optimality may occur here. To determine the behavior of the proposed algorithm and the effect of the proper adjustments of the parameters on the overall behavior of the algorithm settings, different experiments were designed to examine the impact of heuristic information $\beta$, Pheromone trails $\alpha$, and Pheromone evaporation rate $\rho$. Information on these experiments is presented in Table 2 and Fig. 4 shows the relationship between dynamic parameters $\rho, \beta$ and t.

\subsection{An experiment to represent the improve behavior of SACS using the proposed algorithm (ISACS)}

In this experiment, the proposed algorithm was implemented using MATLAB software. The behavior of ants (learners) was simulated, and the choice of input data, such as the

Table 2 Information of tuning parameters experiments

\begin{tabular}{lllllll}
\hline & Number of iteration & Population size & Number of LO & $\rho$ & $\alpha$ & $\beta$ \\
\hline Experiment 1 & 1000 & 50 & 24 & 0.05 & 3.5 & 1 \\
Experiment 2 & 1000 & 50 & 24 & 0.05 & 1 & 1 \\
Experiment 3 & 1000 & 50 & 24 & dynamic & 1.75 & dynamic \\
\hline
\end{tabular}




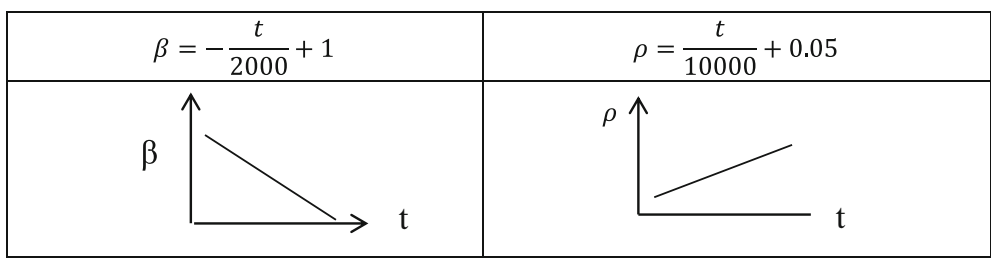

Fig. 4 Relationship between dynamic parameters $\rho, \beta$ and $\mathrm{t}(\mathrm{t}$ is running time)

time between selecting two learning objects $(\mathrm{t})$, total time spent on study and problem solving ( $\mathrm{T}$ ), and the attention and skill of every learner (js), was done from a database randomly generated in a large volume with normal distribution. Score prediction was carried out based on the results of Hong study (1998). Then, given that the new system is a development of the previous system, the previous system was considered as part of the current system in comparing the two algorithms. This means that it is assumed that the previous system's learners are the learners of the new system, for whom parameters related to time $\mathrm{t}, \mathrm{T}$, as well as scores of recitation (score) during learning activity are registered in their profiles. Now the algorithm for updating pheromones will act in two ways. In the first method, it acts in accordance with the SACS algorithm, and only the parameter " $t$ " will be used as input of the pheromone update formula, thus determining the learning paths. In the new method, initially, a local search procedure will be applied for finding the best learners, and then the parameters of $t, T$ and score will be used to update pheromones. This experiment was carried out for the initial population of 50 ants and in 2000 iterations for two algorithms. Learners' performance results in optimal path are shown in the section (6.3).

\section{Results}

\subsection{Results of analyzing the heuristic information value}

The results of Yang's study (2011) show that the Eq. (3) is adapted to the forgetting curve. In this equation, $\lambda=1.25, s=1$ ( $\mathrm{s}$ is a parameter that states the power of memory, and $\lambda$ is a fixed value). Figure 5, shows the comparison of the curves of Eq. (3) and the previous equation proposed in SACS algorithm Eq. (8).

\subsection{Analyzing the results of the algorithm parameters}

In this section, the results of the three experiments, in which algorithm parameters were tuned dynamically, are shown in Table 3 and Fig. 6.

In the first experiment, the algorithm converges quickly with a path and stagnates for each groups of students with similar learning styles, and lose to explore new directions in next iteration. In the second experiment, the behavior of the algorithm for the speed of convergence to an optimal path is not desirable. To improve the algorithm behavior in the final test, the impact of $\beta$ parameter is dynamic, initially high and then decreasing linearly in iterations of the algorithm. This change, prevent the static algorithm behavior. When the optimal path discovered, the beta value reaches zero to reduce the computational overhead system. The evaporation rate $(\rho)$ increases linearly, with 


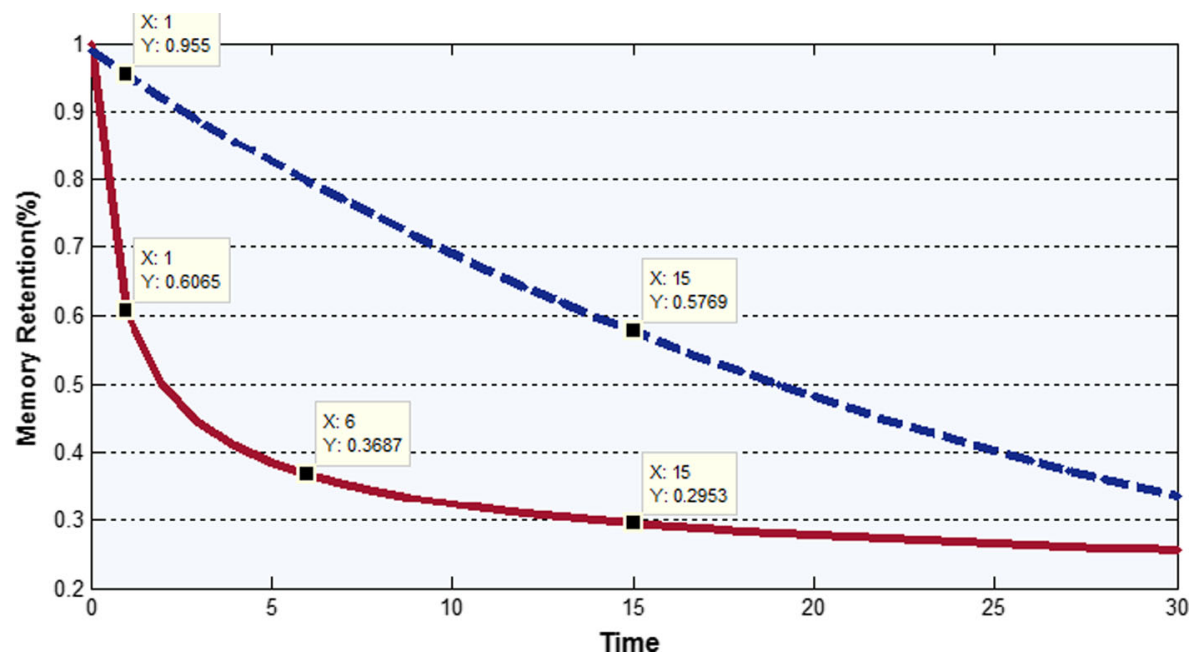

Fig. 5 a The comparison of curves of heuristic values, the solid-line curve is Eq. (3), and the dashed-line curve is Eq. (8) used in SACS algorithm. Comparison of the two charts shows that the curve of Eq. (3) is closer to the values of the Ebbinghaus forgetting curve

each iteration of the algorithm and in the final stages quickly, to prevent from stagnate of the algorithm.

\subsection{The results of comparing the proposed algorithm (ISACS) and SACS}

The implementation result of two algorithms in the optimal path for best learners is presented in Tables 4 and 5.

Comparing the results of the above tables indicates that converged paths for each learning style are not different from other styles, and are also common in some parts of the path. Both types of pheromones (pheromones related to similar learners and pheromone related to all learners who have crossed the edge) are used to highlight the paths in Equation 16 which is used to update the pheromone. Therefore, some parts of the path which are highlighted by dissimilar learners may be common for multiple learning styles. The percentage of convergence for the SACS algorithm is higher than the current algorithm. Local search procedures are used in the proposed algorithm and only those learners who have met the success provision are involved in pheromone updating. Therefore, a fewer number of learners are involved in highlighting the learning paths. As a result, convergence of the algorithm will be done slowly with higher frequency.

Also, comparison of the paths in which convergence has been carried out - i.e. the paths which have been optimized for this algorithm in terms of the total time and score,

Table 3 Of convergence to optimal paths in 1000 the iteration

\begin{tabular}{lll}
\hline$\alpha=1.75, \beta, \rho$ is dynamic & $\alpha=1, \beta=1, \rho=0.05$ & $\alpha=3.5, \beta=1, \rho=0.05$ \\
$78 \%$ & $43 \%$ & $98 \%$
\end{tabular}




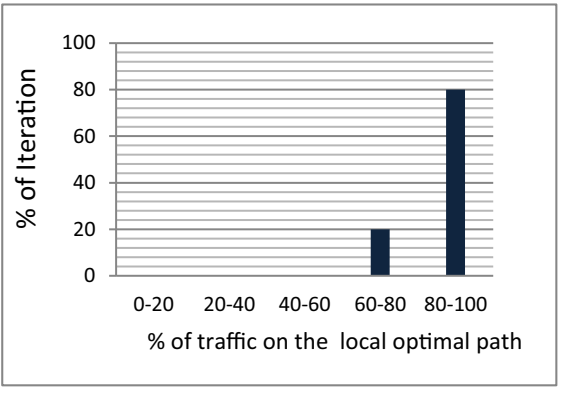

a

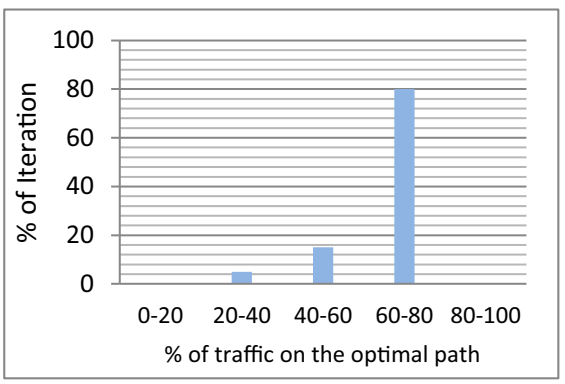

c

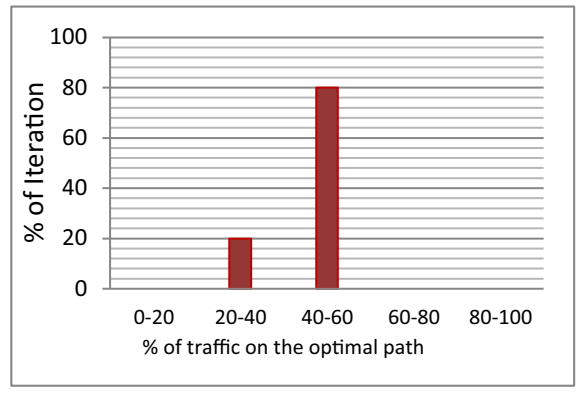

b

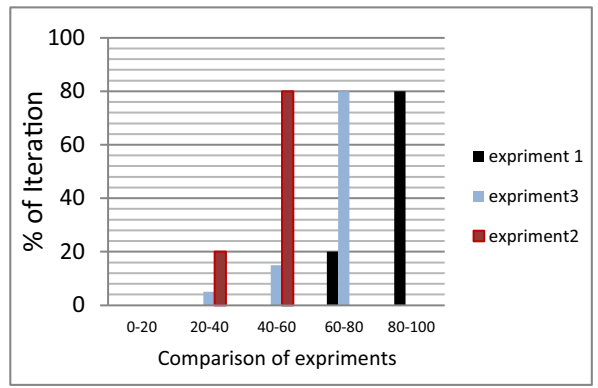

d

Fig. 6 a experiment 1, improper behavior algorithm early stagnation. b. experiment 2, the improper behavior of the algorithm because of slow convergence. c. experiment 3, improve the algorithm by selecting dynamic parameters. d The comparison of experiments

and for the SACS algorithm in terms of the selection time between two learning objects - revealed that the average time $t$ is the same for two algorithms, but the average time $T$ is lower in the proposed algorithm. The average score of learners who have played important roles in the creation of optimal learning paths is higher than the average score of learners who played more active roles in making optimal paths, because optimal learning paths in the proposed algorithm are built by learners who have had higher scores and spent less total time. In the previous algorithm, however, the optimized paths were highlighted by learners who had spent less time making a selection between two contents. Overall, this comparison shows that the changes in the proposed algorithm aim to improve the performance of the previous algorithm and make it more complete.

\section{Conclusion and further work}

Using adaptive learning in learning environments is a useful approach in education systems. The problem is that during the learning process, the learner is faced with a massive amount of learning objects which may not fit to an individual's needs and personality. At present, customized learning objects which adapt to learners' perspectives are a powerful constraint of any e-learning system. Swarm intelligence algorithms, such as ant colony optimization, are capable of modeling student's learning behavior in such a way that creates self-organizing. In this paper, by investigating the previous 
Table 4 Information of the best students in the optimal paths (ISACS algorithm)

\begin{tabular}{lllll}
\hline Learning style/ problem solving style & Optimal learning path & Average t & Average $\mathrm{T}$ & Average score \\
\hline $\mathrm{V} /(\mathrm{I}, \mathrm{T})$ & {$[1,6,9,16,18,22]$} & 0.2870 & 0.3846 & 75.36 \\
$\mathrm{~V} /(\mathrm{I}, \mathrm{F})$ & {$[1,8,9,13,17,23]$} & 0.2909 & 0.3880 & 75.34 \\
$\mathrm{~V} /(\mathrm{E}, \mathrm{T})$ & {$[1,8,10,15,19,23]$} & 0.2821 & 0.3824 & 75.09 \\
$\mathrm{~V} /(\mathrm{E}, \mathrm{F})$ & {$[1,7,9,15,18,21]$} & 0.2839 & 0.3812 & 75.28 \\
$\mathrm{~A} /(\mathrm{I}, \mathrm{T})$ & {$[2,7,10,13,18,22]$} & 0.2856 & 0.3794 & 75.46 \\
$\mathrm{~A} /(\mathrm{I}, \mathrm{F})$ & {$[2,6,9,13,18,21]$} & 0.2837 & 0.3843 & 75.58 \\
$\mathrm{~A} /(\mathrm{E}, \mathrm{T})$ & {$[2,7,12,14,17,21]$} & 0.2744 & 0.3712 & 75.16 \\
$\mathrm{~A} /(\mathrm{E}, \mathrm{F})$ & {$[2,7,12,13,17,21]$} & 0.2744 & 0.3794 & 74.66 \\
$\mathrm{R} /(\mathrm{I}, \mathrm{T})$ & {$[3,8,10,14,19,24]$} & 0.2745 & 0.3912 & 75.01 \\
$\mathrm{R} /(\mathrm{I}, \mathrm{F})$ & {$[3,7,12,15,17,24]$} & 0.2815 & 0.3946 & 75.35 \\
$\mathrm{R} /(\mathrm{I}, \mathrm{F})$ & {$[3,5,9,15,17,24]$} & 0.2846 & 0.4054 & 75.48 \\
$\mathrm{R} /(\mathrm{E}, \mathrm{F})$ & {$[3,6,9,13,20,24]$} & 0.2847 & 0.3931 & 75.15 \\
$\mathrm{~K} /(\mathrm{I}, \mathrm{T})$ & {$[4,5,10,16,18,23]$} & 0.2831 & 0.4029 & 75.58 \\
$\mathrm{~K} /(\mathrm{I}, \mathrm{F})$ & {$[4,7,12,16,20,24]$} & 0.2946 & 0.3813 & 75.00 \\
K/ (E,T) & {$[4,8,10,14,20,22]$} & 0.2932 & 0.3956 & 75.15 \\
K/ (E,F) & {$[4,8,9,13,17,24]$} & 0.2831 & 0.4012 & 74.56 \\
\hline
\end{tabular}

adaptive e-learning systems based on ACO, a new method was proposed that benefits from the advantages of these systems, and which minimizes the drawbacks of previous methods. Course content is personalized based on the VARK learning style, and MBTI problem-solving styles have been used to design learning exercises to meet the needs of learners. The algorithm decides the next learning object, and only paths crossed by learners with a high success level (i.e. a higher score and a lower total of time spent) will be marked by pheromones. The rate of increase in pheromones is also proportional to the obtained score, and is inversely proportional to the spent time. Furthermore, to follow the path of similar ants, learners with similar learning styles may leave a higher ratio of pheromone in paths. Dynamic adjustment of the algorithm parameters has created a new structure that adjusts the search rate in order to find new and optimized paths in a way that all possible paths are investigated prior to reaching convergence. In high iterations, in which the algorithm has recognized the appropriate paths for each group of learners comprehensively, the volatilization rate increases to prevent the algorithm from showing a stagnation behavior. Implementation of the proposed

Table 5 Information of the best students in the optimal paths (SACS algorithm)

\begin{tabular}{lllll}
\hline Learning style & Optimal learning path & Average t & Average T & Average score \\
\hline $\mathrm{V}$ & {$[1,8,10,16,19,21]$} & 0.2837 & 0.5146 & 68.52 \\
$\mathrm{~A}$ & {$[2,6,12,13,19,22]$} & 0.2824 & 0.5012 & 68.38 \\
$\mathrm{R}$ & {$[3,8,11,16,19,21]$} & 0.2829 & 0.4993 & 68.44 \\
$\mathrm{~K}$ & {$[4,7,12,14,18,23]$} & 0.2891 & 0.5007 & 69.04 \\
\hline
\end{tabular}


algorithm using the MATLAB software package shows that this algorithm is capable of finding paths with maximum efficiency and adaptation to learners' traits, the main objective for which it has been designed. Moreover, quantitative comparison of the results of implementing the proposed algorithm along with the SACS algorithm also reflect the good performance of the proposed algorithm in finding optimal learning paths.

In our future work, we will implement the proposed system and practically experiment in a learning environment, so as to thoroughly investigated and analyze learners' behavior and assess their performance.

Open Access This article is distributed under the terms of the Creative Commons Attribution 4.0 International License (http://creativecommons.org/licenses/by/4.0/), which permits unrestricted use, distribution, and reproduction in any medium, provided you give appropriate credit to the original author(s) and the source, provide a link to the Creative Commons license, and indicate if changes were made.

\section{References}

ADL (2004). Advanced distributed learning initiative. Sharable content object reference model (SCORM) 2004, 3rd ed, Overview, ADL Web Site. http://www.adlnet.gov/scorm. Retrieved 10.05.2006.

Blaylock, B., \& Rees, L. (1984). Cognitive style and the usefulness of information. Decision Science, 15(1), 74-91.

DiTiberio, J. (1998). Uses of type in education. MBTI manual: A guide to the development and use of the Myers-Briggs type indicator. Palo Alto: Consulting Psychologists Press.

Dorigo, M. (1992). Optimization, learning and natural algorithms. PhD thesis. Italy: Politecnico di Milano.

Dorigo, M., \& Gambardella, L. M. (1997). Ant colonies for the traveling salesman problem. BioSystems, 43, 73-81.

Dorigo, M., \& Stützle, T. (2004). Ant colony optimization. Cambridge MA: MIT Press.

Dunn, R., \& Dunn, K. (1978). Teaching students through their individual learning styles. Reston: Reston.

Dunn, R., \& Griggs, S. (2003). Synthesis of the Dunn and Dunn learning styles model research: who, what, when, where and so what - The Dunn and Dunn learning styles model and its theoretical cornerstone. New York: St John's University.

Ebbinghaus, H. (1913). Memory: a contribution to experimental psychology. New York: Teachers College, Columbia University.

Felder, R. M. (1993). Reaching the second tier: learning and teaching styles in College Science Education. College Science Teaching, 23(5), 286-290.

Felder, R \& Brent, R. (2005). Understanding student differences. Journal of Engineering Education.

Felder, R. M., \& Silverman, L. K. (1988). Learning and teaching styles in engineering education. Engineering Education, 78(7), 674-681.

Flemming, N. D. (1995). Modes of Presentation (V.A.R.K.) in the Tertiary Classroom. In A. Zelmer (ed.), Research and development in higher education. Proceedings of the annual conference of the higher education and research development society of Australia (HERDSA), vol. 18, pp. 308-313.

Georgieva, G., Todorov, G., \& Smrikarov, A. (2003). A model of a Virtual University: some problems during its development. In Proceedings of the 4th international conference on Computer systems and technologies: e-Learning, Bulgaria: ACM Press.

Ghusoon, S. B., Mohd, S. A., \& Alicia, Y. C. (2013). A conceptual multi-agent framework using ant colony optimization and fuzzy algorithms for learning style detection. Springer-Verlag Berlin Heidelberg, ACDIIDS, Part 2, pp. 549-558.

Grasha, A. F. (1984). Learning styles: the Journey from Greenwich Observatory (1796) to the College classroom. Improving College and University Teaching, 32(1), 46-53.

Gutiérrez, S., Pardo, A., \& Kloos, C. D. (2006). Finding a learning path: toward a swarm intelligence approach. Proceedings of International Conference on Web-based Education'06 (pp.94-99), Puerto Vallarta, Mexico.

Hamdi, M. S. (2007). MASACAD: a multi-agent approach to information customization for the purpose of academic advising of students. Applied Soft Computing, 7, 746-771. 
Harrington, R., \& Loffredo, D. A. (2010). MBTI personality type and other factors that relate to preference for online versus face-to-face instruction, Internet And Higher Education at Science Direct, pp. 89- 95.

Hong, S. (1998). The Relationship between well-Structured and ill-Structured problem solving in multi media simulation. PhD Thesis, Pennsylvania State University.

Huang, M. J., Huang, H. S., \& Chen, M. Y. (2007). Constructing a personalized elearning system based on genetic algorithm and case-based reasoning approach. Expert Systems with Applications, 33, 551-564.

IMS Global Learning Consortium Inc (2003). IMS learning design best practice and implementation guide. Version 1.0 Final Specification.

Jeroen, J. G., \& van Merriënboer, P. A. (2005). Research on cognitive load theory and its design implications for E-learning. ETR\&D, 53(3):5-13. ISSN 1042-1629.

Keefe, J. (1979). Learning style: an overview. NASSP's student learning styles: Diagnosing and prescribing programs, pp. 1-17.

Kirton, M. J. (1987). Cognitive styles and creativity. In S. G. Isaksen (Ed.), Frontiers in creativity research: beyond the basics (pp. 282-304). Buffalo: Bearly Limited.

Kirton, M. (Ed.). (1994). Adaptors and innovators: styles of creativity and problem solving. London: Routledge.

Koper, R., \& Burgos, D. (2005). Designing learning activities: from content-based to context-based learning services. International Journal on Advanced Technology for Learning, 2(3).

Kwasnicka, H., Szul, D., Markowska-Kaczmar, U., \& Myszkowski, P. B. (2008). Learning assistant personalizing learning paths in eLearning environments. Computer Information Systems and Industrial Management Applications.

Landry, J. M. (2011). Learning styles of law enforcement officers, does police work affect how officers learn? Capella University.

MASIE Center (2002). Making sense of learning specifications \& standards: A decision maker's guide to their adoption. Industry Report, <http://www.masie.com/standards/S3_Guide.pdf> Retrieved 10.05.2006.

Maycock, K. (2010). A framework for adaptive e-learning. Ph.D Thesis, Department of Computer Science, National University of Ireland.

Mustafa, A. E. Y. A., \& Mohamed, S. S. (2011). An approach to Adaptive E-Learning Hypermedia System based on Learning Styles (AEHS-LS): implementation and evaluation. International Journal of Library and Information Science, 3(1), 15-28. January 2010.

Myers, I. (1993). Introduction to type. Palo Alto: Consulting Psychologists Press.

Myers, I. B., \& McCaulley, M. H. (1985). Manual: a guide to the development and use of the Myers-Briggs type indicator. Palo Alto: Consulting Psychologists Press.

Paramythis, \& Loidl-Reisinger, S. (2004). Adaptive learning environments and e-Learning standards. Electronic Journal of e-Learning, 2(1), 181-194.

Pham, Q. D., \& Florea, A. M. (2012). An approach for detecting learning styles in learning management systems based on learners' behaviors. In: International Conference on Education and Management Innovation, IPEDR, vol. 30, IACSIT Press, Singapore.

Popescu, E. (2008). Diagnosing students' learning style in an educational hypermedia system. Software Engineering Department, University of Romania.

Pushpa, M. (2012). ACO in e-Learning: Towards an adaptive learning path, Department Of Computer Science, Pondicherry University. International Journal on Computer Science and Engineering (IJCSE), $4(03)$

Schiaffino, S., Garcia, P., \& Amandi, A. (2008). eTeacher: providing personalized assistance to e-Learning students. Elsevier Ltd.

Schreurs, J., \& Moreau, R. (2006). Learning objects (LO) aligning different learning styles. University Hasselt.

Selby, E. C., Treffinger, D. J., Isaksen, S. G., \& Lauer, K. J. (2004a). VIEW technical manual. Sarasota: Center for Creative Learning.

Selby, E. C., Treffinger, D. J., Isaksen, S. G., \& Lauer, K. J. (2004b). Defining and assessing problem-solving style: design and development of new tool. Journal of Creative Behavior, 38, 221-243.

Semet, Y., Lutton, E., \& Collet, P. (2003). Ant colony optimization for e-learning: observing the emergence of pedagogic suggestions. Proceedings of IEEE Swarm Intelligence Symposium'03 (pp. 46-52), Indianapolis, USA.

Sharma, R., Banati, H., \& Bedi, P. (2012). Adaptive content sequencing for e-Learning courses using ant colony optimization. Proceedings of the International Conference on SocProS 2011, AISC 131, pp. 597590, Springer India.

Stewart, C., Cristea, A., Brailsford, T., \& Ashman, H. (2005). Authoring once, delivering many: Creating reusable adaptive courseware. In Web-based education conference WBE'05, Grindelwald, Switzerland. 
Tseng, S. S., Sue, P. C., Su, J. M., Weng, J. F., \& Tsai, W. N. (2005). A new approach for constructing the concept map. Journal of Computers \& Education.

Van den Berg, B., Van Es, R., Tattersall, C., Janssen, J., Manderveld, J., Brouns, F., Kurvers, H., \& Koper, R. (2005). Swarm-based sequencing recommendations in e-learning. Proceedings of International Conference on Intelligence Systems Design and Applications'05 (pp. 488-493), Wroclaw, Poland.

Wang, T. I., Wang, K. T., \& Huang, Y. M. (2008). Using a style-based ant colony system for adaptive learning, expert systems with applications. Journal of ELSEVIR, 34(4), 2449-2464.

Wong, L. H., \& Looi, C. K. (2009). Adaptable learning pathway generation white ant colony optimization. Educational Technology \& Society, 12(3), 309-326.

$\mathrm{Xu}, \mathrm{D}$., \& Wang, H. (2006). Intelligent agent supported personalization for virtual learning environments. Decision Support Systems, 42, 825-843. 